\title{
Novel diffusive gradients in thin films technique to assess labile sulfate in soil
}

\author{
Ondrej Hanousek $^{1,2} \cdot$ Sean Mason ${ }^{3} \cdot$ Jakob Santner $^{4}$ (D) Md Mobaroqul Ahsan Chowdhury ${ }^{3}$. \\ Torsten W. Berger ${ }^{2}$ - Thomas Prohaska ${ }^{1}$
}

Received: 2 June 2016 / Revised: 7 July 2016 / Accepted: 14 July 2016 /Published online: 4 August 2016

(C) The Author(s) 2016. This article is published with open access at Springerlink.com

\begin{abstract}
A novel diffusive gradients in thin films (DGT) technique for sampling labile soil sulfate was developed, based on a strong basic anion exchange resin (Amberlite IRA-400) for sulfate immobilization on the binding gel. For reducing the sulfate background on the resin gels, photopolymerization was applied instead of ammonium persulfate-induced polymerization. Agarose cross-linked polyacrylamide (APA) hydrogels were used as diffusive layer. The sulfate diffusion coefficient in APA gel was determined as $9.83 \times 10^{-6} \pm 0.35 \times 10^{-6} \mathrm{~cm}^{2} \mathrm{~s}^{-1}$ at $25^{\circ} \mathrm{C}$. The accumulated sulfate was eluted in $1 \mathrm{~mol} \mathrm{~L}^{-1}$ $\mathrm{HNO}_{3}$ with a recovery of $90.9 \pm 1.6 \%$. The developed method was tested against two standard extraction methods for soil sulfate measurement. The obtained low correlation coefficients indicate that DGT and conventional soil test methods assess differential soil sulfate pools, rendering DGT a potentially important tool for measuring labile soil sulfate.
\end{abstract}

Keywords Diffusive gradients in thin films (DGT) · ICP-MS · Sulfur $\cdot$ Sulfate $\cdot$ Soil

Ondrej Hanousek and Sean Mason contributed equally to this work.

Jakob Santner

jakob.santner@boku.ac.at

1 Department of Chemistry - VIRIS Laboratory, University of Natural Resources and Life Sciences Vienna, Konrad-Lorenz-Strasse 24, 3430 Tulln, Austria

2 Institute of Forest Ecology, University of Natural Resources and Life Sciences Vienna, Peter-Jordan-Strasse 82, 1190 Vienna, Austria

3 School of Agriculture, Food and Wine, University of Adelaide and the Waite Research Institute, Adelaide, South Australia 5064, Australia

4 Division of Agronomy, University of Natural Resources and Life Sciences Vienna, Konrad-Lorenz-Strasse 24, 3430 Tulln, Austria

\section{Introduction}

Sulfur (S) is a plant macronutrient as part of e.g. amino acids, proteins, and coenzymes. It is involved in the plant metabolism as well as in the response to oxidative stress [1]. Sulfur deficiency in arable soils has been reported to become one of the major limitations in crop production [2]. Plants take up $\mathrm{S}$ as sulfate $\left(\mathrm{SO}_{4}{ }^{2-}\right)$ from the soil porewater. Therefore, determination of labile soil $\mathrm{SO}_{4}{ }^{2-}$ is essential for the investigation of $\mathrm{S}$ phytoavailability in soils [1-3].

Batch extraction techniques using different extractant solutions, e.g., $\mathrm{H}_{2} \mathrm{O}, 0.03 \mathrm{~mol} \mathrm{~L}^{-1} \mathrm{KH}_{2} \mathrm{PO}_{4}$, and $1 \mathrm{~mol} \mathrm{~L}^{-1} \mathrm{HCl}$ [4, $5]$, are the most common methods to assess readily available, adsorbed, and carbonate-occluded soil sulfate, respectively. Common agricultural $\mathrm{S}$ testing methods include the $\mathrm{KCl}-40$ test, which uses $0.25 \mathrm{~mol} \mathrm{~L}^{-1} \mathrm{KCl}$ as an extractant [6]. This method was proposed to be more representative for plantavailable soil $\mathrm{S}$ than the MCP-S method (using $0.01 \mathrm{~mol} \mathrm{~L}^{-1}$ $\left.\mathrm{Ca}\left(\mathrm{H}_{2} \mathrm{PO}_{4}\right)_{2}\right)$, as $\mathrm{KCl}-40$ provides a measure of adsorbed and soluble $\mathrm{SO}_{4}{ }^{2-}$, including gypsum.

Tension lysimeters or suction cups are alternative methods for assessing dissolved soil $\mathrm{S}$ by directly taking soil porewater samples [1, 3]. However, they do not account for the reversibly adsorbed fraction of soil $\mathrm{SO}_{4}{ }^{2-}$. Sampling strategies employing ion resins as $\mathrm{SO}_{4}{ }^{2-}$ sinks, which deplete $\mathrm{SO}_{4}{ }^{2-}$ in the soil porewater and thereby induce desorption from the solid phase, have been developed to additionally account for this soil $\mathrm{SO}_{4}{ }^{2-}$ pool [7]. This approach has the additional advantage of pre-concentrating $\mathrm{SO}_{4}{ }^{2-}$ on the resin. However, if the resin is directly exposed to the soil $[7,8]$, it may be easily contaminated with soil particles [8]. Competition of other anions (e.g., phosphate, nitrate) for binding sites of the resin may also lead to sampling artefacts [9].

Diffusive gradients in thin films (DGT) is an advanced sink technique, in which the resin is embedded in a hydrogel layer and 
is covered by a pure hydrogel disc and a protective membrane. This setup prevents particle contamination effectively and allows for the calculation of the time-averaged analyte $\left(\mathrm{SO}_{4}{ }^{2-}\right)$ concentration due to the well-defined diffusion geometry [10]:

$c_{\mathrm{DGT}}=\frac{M \cdot \Delta g}{D \cdot A \cdot t}$

$M$ is the mass of analyte bound on the resin layer, $\Delta g$ is the diffusive layer thickness, $D$ is the diffusion coefficient of the analyte in the diffusive layer, $A$ is the sampling area, and $t$ is the sampling time.

The DGT methodology has been shown to perform exceedingly well in assessing the bioavailable solute fraction if the solute availability is limited by diffusion [11]. Several studies demonstrated that soil phosphate assessed by DGT correlated better with plant phosphate uptake [11-13] and with crop yield responses to applied P [14] compared to conventional batch extractions or other resin-based sampling techniques $[11,13]$. Guppy and Blair [15] have shown that established methods (KCl-40 and MCP) were poor at predicting maize $\mathrm{S}$ uptake and responses to $\mathrm{S}$ applications in a short-term glasshouse experiment. Therefore, an improved, simple, and quick laboratory method like DGT for determining available $\mathrm{S}$ could have significant benefits.

No DGT method for $\mathrm{SO}_{4}{ }^{2-}$ sampling is currently available. The only $\mathrm{S}$ species for which a DGT method is available is sulfide, which is sampled by the conversion of $\mathrm{AgI}$ to $\mathrm{Ag}_{2} \mathrm{~S}$ [16]. As sulfate sorption to oxide minerals (e.g., ferrihydrite, zirconium oxide) $[17,18]$, which have been used for measuring oxyanions (e.g., $\mathrm{PO}_{4}{ }^{3-}$ and $\mathrm{AsO}_{4}{ }^{3-}$ ) by DGT so far, is weak, a general anion exchange resin is the material of choice for sampling sulfate with DGT.

In this study, we present a novel DGT technique for the sampling of labile soil $\mathrm{SO}_{4}{ }^{2-}$. The developed anion exchange resin gel was characterized (regarding its $\mathrm{SO}_{4}{ }^{2-}$ uptake capacity, $\mathrm{pH}$ working range, and elution efficiency) for applications in soil. Comparison of its performance with traditional techniques assessing soil $\mathrm{SO}_{4}{ }^{2-}$, the $\mathrm{KCl}-40$, and $\mathrm{MCP}$ extractions, shows that DGT samples a different $\mathrm{SO}_{4}{ }^{2-}$ pool and is therefore a potential alternative for soil $\mathrm{SO}_{4}{ }^{2-}$ testing.

\section{Materials and methods}

\section{General laboratory procedures}

All consumables were double acid washed using $10 \%(w / w)$ and $1 \%(w / w) \mathrm{HNO}_{3}$ (p. a., Merck, Darmstadt, DE) and rinsed with laboratory water type $\mathrm{I}\left(0.055 \mu \mathrm{S} \mathrm{cm}^{-1}\right.$; TKAGenPure, Niederelbert, DE) before use. Laboratory water type I was used for preparation of all standard solutions, for soil extractions, and for water saturation of soil samples.
Laboratory water type $\mathrm{I}$ and $\mathrm{HNO}_{3}$ were further purified by a sub-boiling distillation system (Milestone Inc., Shelton, CT, USA) and used for the elution of $\mathrm{SO}_{4}{ }^{2-}$ from the resin gel $\left(1 \mathrm{~mol} \mathrm{~L}^{-1} \mathrm{HNO}_{3}\right)$ and for microwave-assisted digestions (Multiwave 3000, Anton Paar, Graz, AT).

\section{Diffusive and resin gel preparation}

Agarose cross-linked polyacrylamide (APA) diffusive hydrogels of $0.8 \mathrm{~mm}$ thickness were prepared according to [10] and cut to discs. Amberlite IRA-400 (chloride form, Sigma-Aldrich, Buchs, $\mathrm{CH}$ ) resin was selected as a binding agent for $\mathrm{SO}_{4}{ }^{2-}$. The resin was ground with a ball mill for $10 \mathrm{~min}$, passed through a $200-\mu \mathrm{m}$ sieve, and washed in $10 \% \mathrm{HCl}$ (p.a., Merck), repeating this step twice followed by four rinses with pure water, to reduce the background $\mathrm{S}$ on the resin.

The common acrylamide polymerization technique used for DGT gels applies ammonium persulfate (APS) as initiator [10]. This approach is not suitable for preparing resin gels for the sampling of $\mathrm{SO}_{4}{ }^{2-}$, as elevated background $\mathrm{S}$ levels on the binding gel can be expected. To reduce background $\mathrm{S}$ levels, photopolymerization using riboflavin ((-)-riboflavin, SigmaAldrich) as photoinitator was applied. The polymerization was started through the decomposition of riboflavin upon exposition to a light source. A detailed study on the riboflavininitiated polymerization of acrylamide was published e.g. by Oster et al. [19].

Three grams (wet weight) of ground and washed Amberlite IRA-400 were mixed with $10 \mathrm{~mL}$ gel solution prepared as described in [10] and $60 \mu \mathrm{L}$ of riboflavin solution $(0.01 \mathrm{~g}$ riboflavin in $10 \mathrm{~mL} \mathrm{H}_{2} \mathrm{O}$ ) and $20 \mu \mathrm{L}$ of tetramethylethylendiamine (TEMED; VWR Int., Randor, USA) were added. The solution was shaken well and cast between two acid-washed glass plates $(6 \times 20 \mathrm{~cm})$ separated by a $U$-shaped acid-washed plastic spacer $(0.4 \mathrm{~mm}$ thickness). The glass plate with the gel solution was left under fluorescent light overnight. Gels appeared to set after about $1 \mathrm{~h}$. The resin gels produced in this way were relatively weak and subject to tearing. While avoiding the binding of $\mathrm{SO}_{4}{ }^{2-}$ from APS to the resin gels was important for preventing elevated $\mathrm{S}$ background levels, such precautions are not necessary for diffusive gels, which have no capability for $\mathrm{SO}_{4}{ }^{2-}$ binding. Therefore the diffusive gels used in this study were produced using the classical procedure [10]. Any residual S introduced as APS was washed off the diffusive gels during the gel hydration step. A $10 \mathrm{mmol} \mathrm{L}^{-1} \mathrm{NaNO}_{3}$ solution was used for storage of all gels (Reagent Plus, Sigma-Aldrich).

Polyethersulfone filters $(0.45 \mu \mathrm{m}$ pore size, $0.13 \mathrm{~mm}$ thick, Sartorius Stedim, Goettingen, DE) were used as a protective membrane. The filters were washed with $1 \mathrm{~mol} \mathrm{~L}^{-1} \mathrm{HNO}_{3}$ overnight and stored in $10 \mathrm{mmol} \mathrm{L}^{-1} \mathrm{NaNO}_{3}$. DGT samplers (DGT Research Ltd., Lancaster, UK) were used for both 
solution and soil tests. A schematic of the DGT device is pictured in Fig. 1a. Figure 1b shows the application to soil (see "Comparison of DGT S with conventional soil S extraction techniques" section).

\section{Evaluation of DGT sampling}

\section{Sulfur background level}

The sulfur contents in the protective membrane (acid-washed and unwashed), in the diffusive gel, and in the resin gel (S background concentrations) were determined after elution in $10 \mathrm{~mL} 1 \mathrm{~mol} \mathrm{~L}^{-1} \mathrm{HNO}_{3}$ for $16 \mathrm{~h}$ and calculated as $\mathrm{S}$ amount per membrane or gel disc. The $\mathrm{S}$ content of the eluent was used to determine the instrument limit of detection of the inductively coupled plasma mass spectrometer (ICP-MS, see "ICP-MS" section) (limit of detection $($ LOD $)=$ average eluent $\mathrm{S}$ content $+3 \times$ standard deviation).

The method blank (resin gel, diffusive gel, and protective membrane in DGT sampler placed for $4 \mathrm{~h}$ in a moist plastic bag at $21^{\circ} \mathrm{C}$ ) was measured in $10 \mathrm{~mL} 1 \mathrm{~mol} \mathrm{~L}^{-1} \mathrm{HNO}_{3}$ eluate of the resin gel and calculated as $\mathrm{S}$ amount per resin gel disc. The $\mathrm{S}$ contents were used to determine the method limit of detection for S by ICP-MS (method limit of detection $(\mathrm{MDL})=$ average method blank $\mathrm{S}$ content $+3 \times$ standard deviation).

\section{Resin gel elution efficiency $(R)$}

A recovery experiment using a ${ }^{35} \mathrm{~S}$ radiotracer (Perkin Elmer, Waltham, MA, USA) was conducted. $10 \mathrm{~mL} 0.5 \mathrm{mg} \mathrm{L}^{-1} \mathrm{~S}$

\section{a}

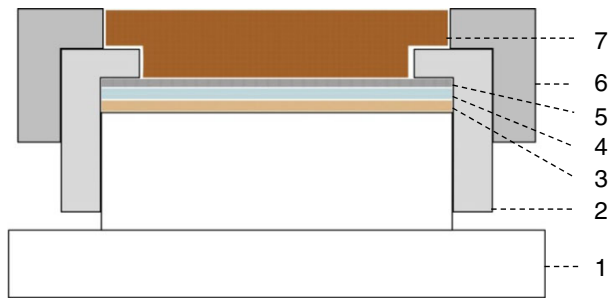

\section{b}

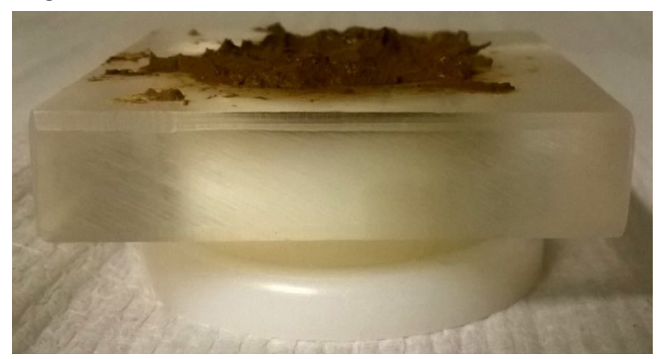

Fig. 1 DGT sampling device schematic (a): 1 piston, 2 outer sleeve with sampling window, 3 resin (Amberlite IRA-400) gel, 4 diffusive (APA) gel, 5 protective membrane, 6 plastic frame to hold the soil sample in place, 7 soil sample. Application of the DGT device to soil (b)
$\left(\left(\mathrm{NH}_{4}\right)_{2} \mathrm{SO}_{4}\right.$, p.a., Merck) and $10 \mathrm{~mL} 10 \mathrm{mg} \mathrm{L}^{-1} \mathrm{~S}$ $\left(\left(\mathrm{NH}_{4}\right)_{2} \mathrm{SO}_{4}\right)$ solutions were spiked with $\sim 980 \mathrm{~Bq}{ }^{35} \mathrm{~S}$. A resin gel was immersed in each solution. The solutions were shaken for $4 \mathrm{~h}$ and the gels were eluted in $10 \mathrm{~mL} 1 \mathrm{~mol} \mathrm{~L}^{-1}$ $\mathrm{HNO}_{3}$ for $16 \mathrm{~h}$ subsequently. This experiment was repeated five times.

\section{Diffusion coefficient (D)}

The diffusion coefficient $D$ of $\mathrm{SO}_{4}{ }^{2-}$ in APA gel was determined using a diffusion cell [20]. The cell consisted of two $110 \mathrm{~mL}$ Perspex containers, each with a 1.59 -cm-diameter opening. A 2.5 -cm-diameter diffusive gel disc was placed between the openings and the containers were clamped together. One hundred milliliters of water ( $\mathrm{pH} 5.6)$ were introduced into one of the containers and the tightness of the clamping was checked. Then, $100 \mathrm{~mL}\left(\mathrm{NH}_{4}\right)_{2} \mathrm{SO}_{4}$ (p.a., Merck) solution (pH 5.6) was introduced into the second container. To ensure that $D$ is not concentration dependent, sulfate solutions of 1, 10, and $45 \mathrm{mg} \mathrm{L}^{-1} \mathrm{~S}$ were used. Each sulfate solution was spiked with $\sim 370 \mathrm{k} \mathrm{Bq}{ }^{35} \mathrm{~S}$. Solutions in both containers were stirred continuously. Subsamples were taken from both containers in time intervals of about $30 \mathrm{~min}$ to follow the diffusion of $\mathrm{S}$ through the APA gel. $D$ and its uncertainty were calculated as described in [21]. The final coefficient $D_{25}$ was calculated as a mean value of the diffusion coefficients determined in the 1,10 , and $45 \mathrm{mg} \mathrm{L}^{-1} \mathrm{~S}$ solutions at $25{ }^{\circ} \mathrm{C}$. The $D$ value in further experiments was calculated from $D_{25}$ by temperature adjustment using Eq. 2 [10]:

$$
\begin{aligned}
\log D_{t}= & \frac{1.37(t-25)+8.36 \times 10^{-4}(t-25)^{-2}}{109+t} \\
& +\log \frac{D_{25}(273+t)}{298}
\end{aligned}
$$

pH working range

Sulfate as $\left(\mathrm{NH}_{4}\right)_{2} \mathrm{SO}_{4}$ was dissolved in laboratory water type I to reach a $\mathrm{S}$ concentration of $4-5 \mathrm{mg} \mathrm{L}^{-1}$. The solutions (3 $\mathrm{L}$ each) were stirred until equilibrium with air was reached and $\mathrm{pH}$ was stable. The $\mathrm{pH}$ of the solutions was set to $2.98,3.48$, $3.55,3.97,4.00,5.00,5.10,5.60,6.12,7.02,7.40,8.18,8.34$, and 9.05 using dilute $\mathrm{HNO}_{3}$ and $\mathrm{NaOH}$. Three to four DGT samplers were exposed to each solution for $4 \mathrm{~h}$. The temperature was monitored throughout the experiments. The calculated $c_{\text {DGT }}$ values (Eq. 1) were compared to the $\mathrm{S}$ concentration in the corresponding immersion solution, $c_{\text {soln }}$.

\section{Gel capacity}

A synthetic soil solution was prepared for testing the resin gel capacity for $\mathrm{SO}_{4}{ }^{2-}$ uptake under realistic conditions, i.e., 
taking the competing anion species chloride, nitrate, and phosphate into account. The concentration of $\mathrm{SO}_{4}{ }^{2-}$ was chosen based on typical porewater $\mathrm{SO}_{4}{ }^{2-}$ concentrations [22]. For obtaining a realistic and conservative estimate of the gel $\mathrm{SO}_{4}{ }^{2-}$ capacity, concentrations of $\mathrm{Cl}^{-}, \mathrm{NO}_{3}{ }^{-}$, and $\mathrm{PO}_{4}{ }^{3-}$, based on upper level of the concentration ranges of own and literature soil solution data $[3,22]$, were chosen. Sulfate as $\left(\mathrm{NH}_{4}\right)_{2} \mathrm{SO}_{4}$ was dissolved in laboratory water type I $(6 \mathrm{~L})$ to reach a $\mathrm{SO}_{4}{ }^{2-}$ concentration of $15 \mathrm{mg} \mathrm{L}^{-1}$. $\mathrm{NaCl}, \mathrm{NaNO}_{3}$, and $\mathrm{KH}_{2} \mathrm{PO}_{4}$ were added to the $\mathrm{SO}_{4}{ }^{2-}$ containing solution to reach concentrations of 9.0,60, and $7.5 \mathrm{mg} \mathrm{L}^{-1}$ of $\mathrm{Cl}^{-}, \mathrm{NO}_{3}^{-}$, and $\mathrm{PO}_{4}{ }^{3-}$, respectively. DGT samplers (21 in total) were placed into this solution. After 3, 6, 9, 15, 24, 39, and $48 \mathrm{~h}$, three samplers were taken out at a time. Temperature and $\mathrm{pH}$ were monitored during the experiment. The resin gels were eluted in $1 \mathrm{~mol} \mathrm{~L}^{-1} \mathrm{HNO}_{3}$ subsequently. The content of $\mathrm{SO}_{4}{ }^{2-}, \mathrm{Cl}^{-}$, and $\mathrm{PO}_{4}{ }^{3-}$ in the eluates was measured $\left(\mathrm{NO}_{3}{ }^{-}\right.$content could not be measured as $\mathrm{HNO}_{3}$ was used for elution). The gel capacity was estimated as the highest mass accumulated on the gel that did not differ significantly from the theoretical mass uptake according to Eq. 1.

\section{Analyses}

\section{ICP-MS}

A single collector sector field ICP-MS (Element XR, Thermo Fisher Scientific, Waltham, MA, USA) was used for S quantification in standard solutions and resin gel eluates during method development in the VIRIS Laboratory, Tulln (AT). External calibration $\left(0-3 \mathrm{mg} \mathrm{S} \mathrm{L}^{-1}\right)$ and internal standardization (using $1 \mu \mathrm{g} \mathrm{L}^{-1} \mathrm{In}$ ) were applied. The instrumental LOD was $3 \mu \mathrm{g} \mathrm{S} \mathrm{L}^{-1}$.

\section{${ }^{35}$ S radiotracer}

Isotope dilution using ${ }^{35} \mathrm{~S}$ was used when very low $\mathrm{S}$ concentrations were expected (determination of diffusion coefficient) and for validation of some data obtained by ICP-MS measurement (elution efficiency). A liquid scintillation counter TriCarb 2910 TR (PerkinElmer) was used for measuring the beta radiation emitted by ${ }^{35} \mathrm{~S}$. Measurements were performed on a comparative basis, i.e., the activity of the eluates was compared to the activity of immersion solutions for the determination of the elution efficiency. The gradual increase of activity in subsamples in time was used for determination of the diffusion coefficient.

\section{ICP-OES}

All DGT eluents and extraction solutions from the soil survey (see "Comparison of DGT S with conventional soil S extraction techniques" section) were measured for their S content using ICP-OES (Optima 7000 DV, PerkinElmer) at $181.975 \mathrm{~nm}$ at the University Adelaide (AU). External calibration (0-10 $\left.\mathrm{mg} \mathrm{S} \mathrm{L}^{-1}\right)$ was applied. The instrumental limit of detection was $20 \mu \mathrm{g} \mathrm{S} \mathrm{L}^{-1}$.

\section{Uncertainty estimation}

The calculation of the combined uncertainty of the elution efficiency $\left(u_{R}\right.$, Eq. 3) was based on the combination of the measurement repeatability $\left(\mathrm{SD}_{1}, n=5\right)$ and reproducibility $\left(\mathrm{SD}_{2}, n=3\right)$, combining thus both sample heterogeneity and measurement reproducibility:

$u_{R}=\sqrt{\mathrm{SD}_{1}^{2}+\mathrm{SD}_{2}^{2}}$

The uncertainty of the quantitative measurement was calculated by applying the approach of partial derivatives $\left(u_{c \text { DGT }}\right.$, Eq. 4) based on [21]. Its calculation included the uncertainties of S quantification ( $u_{\text {MEAS }}$, which comprises measurement precision of analyte and of internal standard, blank correction uncertainty, and uncertainty of calibration), the uncertainty of the diffusive layer thickness $\left(u_{\mathrm{DL}}\right)$, the uncertainty of the sampling window surface area $\left(u_{\mathrm{A}}\right)$ and the uncertainty of the diffusion coefficient $\left(u_{\mathrm{D}}\right.$, comprising the uncertainty of the slope of the mass vs. time line, of the thickness of the diffusive gel, of the surface area of the connection of the diffusion cell halves, and of the original concentration of $\mathrm{S}$ in the solution), the sampling time $\left(u_{\mathrm{t}}\right)$, and the elution efficiency $\left(u_{\mathrm{R}}\right)$ :

$\frac{u_{c \mathrm{DGT}}}{c_{\mathrm{DGT}}}=\sqrt{\left(\frac{u_{\mathrm{MEAS}}}{c_{S}}\right)^{2}+\left(\frac{u_{\mathrm{DL}}}{\mathrm{DL}}\right)^{2}+\left(\frac{u_{A}}{A}\right)^{2}+\left(\frac{u_{D}}{D}\right)^{2}+\left(\frac{u_{t}}{t}\right)^{2}+\left(\frac{u_{R}}{R}\right)^{2}}$

where $c_{\mathrm{S}}$ is the determined $\mathrm{S}$ concentration in the eluate, $\mathrm{DL}$ is the diffusive layer thickness, $A$ is the sampling window area, $D$ is the diffusion coefficient, $t$ is the sampling time, and $R$ is the elution efficiency.

Estimation of the uncertainty of the $c_{\mathrm{DGT}} / c_{\text {soln }}$ ratio, which was e.g. used for determining the $\mathrm{pH}$ working range, comprised both the uncertainty of the $c_{\text {DGT }}$ value $\left(u_{c \text { DGT }}\right.$, Eq. 4$)$ and the uncertainty of the determination of the $\mathrm{S}$ concentration in the immersion solution ( $u_{\text {MEAS2 }}$, which comprises measurement precision of analyte and of internal standard, blank correction uncertainty, and uncertainty of calibration).

$\frac{u\left(c_{\mathrm{DGT}} / c_{\mathrm{soln}}\right)}{c_{\mathrm{DGT}} / c_{\mathrm{soln}}}=\sqrt{\left(\frac{u_{\mathrm{cDGT}}}{c_{\mathrm{DGT}}}\right)^{2}+\left(\frac{u_{\mathrm{MEAS} 2}}{c_{\mathrm{soln}}}\right)^{2}}$

Significance of a difference between mean values $\left(c_{\mathrm{DGT}} / c_{\text {Soln }}\right.$ vs. 1.0 line in $\mathrm{pH}$ working range determination and experimental vs. theoretical DGT uptake in gel capacity determination) was tested with respect to the expanded uncertainties $\left(U=2 \times u_{X}\right)$ of the mean values 
to cover $95 \%$ confidence interval. Two mean values were significantly different, if

$\left|m_{1}-m_{2}\right|>\sqrt{U_{m 1}^{2}+U_{m 2}^{2}}$

where $m_{1}$ and $m_{2}$ represent the mean values and $U_{\mathrm{m} 1}$ and $U_{\mathrm{m} 2}$ their expanded uncertainties [23].

\section{Comparison of DGT S with conventional soil S extraction techniques}

We assessed the relation of DGT sampled $\mathrm{S}$ and $\mathrm{S}$ extracted by two conventional soil extraction methods (KCl-40, MCP) of eight agricultural soils (see Table 1) from major cropping regions in Australia. The soil parameters were determined by standard methods following [24]. To determine $\mathrm{S}$ by KCl-40, $4.5 \mathrm{~g}$ of air-dried soil were extracted in $30 \mathrm{~mL} 0.25 \mathrm{~mol} \mathrm{~L}^{-1}$ $\mathrm{KCl}$ at $40{ }^{\circ} \mathrm{C}$. The mixture was incubated for $3 \mathrm{~h}$ at $40^{\circ} \mathrm{C}$ and was repeatedly shaken by hand. The supernatant was separated by centrifugation. To determine MCP-S, $20 \mathrm{~g}$ of air-dried soil was mixed with $100 \mathrm{~mL} 0.01 \mathrm{~mol} \mathrm{~L}^{-1} \mathrm{Ca}\left(\mathrm{H}_{2} \mathrm{PO}_{4}\right)_{2}$ at $\mathrm{pH} 4$. The mixture was shaken over-head for $17 \mathrm{~h}$. The supernatant was separated by centrifugation [24]. For the DGT technique, soils were moistened to $100 \%$ water holding capacity (WHC) 1 day prior to deployment. Six DGT devices were deployed on each soil for $6 \mathrm{~h}$ at a constant temperature of $21{ }^{\circ} \mathrm{C}$ (see Fig. 1b). After deployment, DGT devices were rinsed with laboratory water type I and the binding gels were retrieved and eluted.

\section{Results}

\section{Blank levels, LOD, diffusion coefficient, elution efficiency}

The background $\mathrm{S}$ signals measured in the eluent $\left(1 \mathrm{~mol} \mathrm{~L}^{-1}\right.$ $\mathrm{HNO}_{3}$ ), in eluates of the acid-washed membrane, and of the diffusive gel were below the instrument limit of detection of ICP-MS (see Fig. 2). The background S content of the

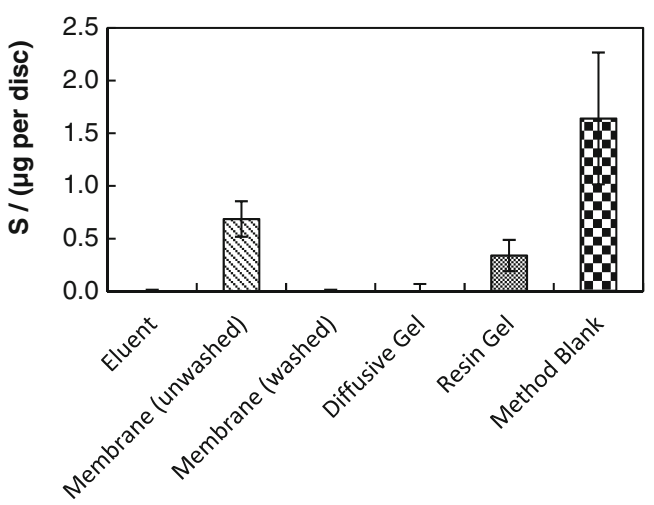

Fig. 2 Background signal of the eluent $\left(1 \mathrm{~mol} \mathrm{~L}^{-1} \mathrm{HNO}_{3}\right)$ and $\mathrm{S}$ loadings of eluted membranes and gels. Washed membrane and diffusive gel are below instrument LOD. Error bars are $1 \mathrm{SD}(n=4)$

unwashed protective membrane and resin gel reached $0.69 \pm$ $0.17 \mu \mathrm{g} \mathrm{S}$ per membrane disc and $0.34 \pm 0.15 \mu \mathrm{g} \mathrm{S}$ per gel disc (average $\pm 1 \mathrm{SD}$ ), respectively.

The MDL was $0.29 \mathrm{mg} \mathrm{S} \mathrm{L}^{-1}$. The $\mathrm{S}$ loading of the resin gel in the method blank was $1.64 \pm 0.63 \mu \mathrm{g} \mathrm{S}$ per gel disc (average $\pm 1 \mathrm{SD}$ ). For some gel discs, the loading reached up to $2.23 \mu \mathrm{g} \mathrm{S}$. However, some batches of the resin gel showed $\mathrm{S}$ loadings below the instrument LOD.

The mass $\mathrm{S}$ diffused through the APA diffusive gel over time is displayed in Fig. 3. The diffusion coefficient of $\mathrm{SO}_{4}{ }^{2-}$ at $25{ }^{\circ} \mathrm{C}\left(D_{25}\right)$ calculated from these slopes was $9.83 \times 10^{-6} \pm 0.35 \times 10^{-6} \mathrm{~cm}^{2} \mathrm{~s}^{-1}\left(u_{c}\right)$. The main contributor (about $90 \%$ ) to the combined uncertainty was the uncertainty of the correlation between time and mass diffused through the gel.

The elution efficiency $R$ was $90.9 \pm 1.6 \%\left(u_{c}\right)$. These values, together with their uncertainties, were applied for further calculations.

\section{pH working range}

The relative combined uncertainty of the $c_{\mathrm{DGT}} / c_{\text {soln }}$ ratio was $8.9 \%$, and the major contributor to the uncertainty was the determination of individual $c_{\mathrm{DGT}}$ values. The relative

Table 1 Soil properties

\begin{tabular}{lllllllll}
\hline Soil name & Abbreviation & $\begin{array}{l}\text { State of origin } \\
\text { (Australia) }\end{array}$ & Texture & $\begin{array}{l}\text { Clay } \\
\%\end{array}$ & $\begin{array}{l}\mathrm{WHC} \\
\%\end{array}$ & $\begin{array}{l}\mathrm{pH} \\
\left(\mathrm{CaCl}_{2}\right)\end{array}$ & $\begin{array}{l}C_{\text {org }} \\
\%\end{array}$ & $\begin{array}{l}N_{\text {tot }} \\
\%\end{array}$ \\
\hline Birchip & BI & VIC & Medium clay & 31 & 24.9 & 7.7 & 0.75 & 0.13 \\
Hart & HA & SA & Medium clay & 38 & 52.8 & 6.4 & 1.49 & 0.16 \\
Karoonda & KA & SA & Sand & 2 & 20.1 & 5.4 & 0.39 & 0.08 \\
Keith & KE & SA & Sandy clay & 15 & 20.2 & 5.0 & 1.94 & 0.17 \\
Lake Bolac & LB & VIC & Sand & 3 & 39.4 & 5.9 & 1.33 & 0.15 \\
Mt Barker & MB & WA & Sand & 12 & 28.7 & 5.6 & 2.49 & 0.20 \\
Otterbourne & OT & ACT & Medium clay & 13 & 32.5 & 5.4 & 3.00 & - \\
Tumby Bay & TB & SA & Sandy clay & 17 & 22.4 & 4.6 & 3.00 & 0.23 \\
\hline
\end{tabular}

WHC water holding capacity 
Fig. 3 Mass transport of sulfate$\mathrm{S}$ through the APA diffusive gel over time. Using the slope of the regression line and the initial $\mathrm{S}$ concentration (a $1 \mathrm{mg} \mathrm{L}^{-1}$, b $10 \mathrm{mg} \mathrm{L}^{-1}$, c $45 \mathrm{mg} \mathrm{L}^{-1}$ ), $D$ was calculated according to [20]
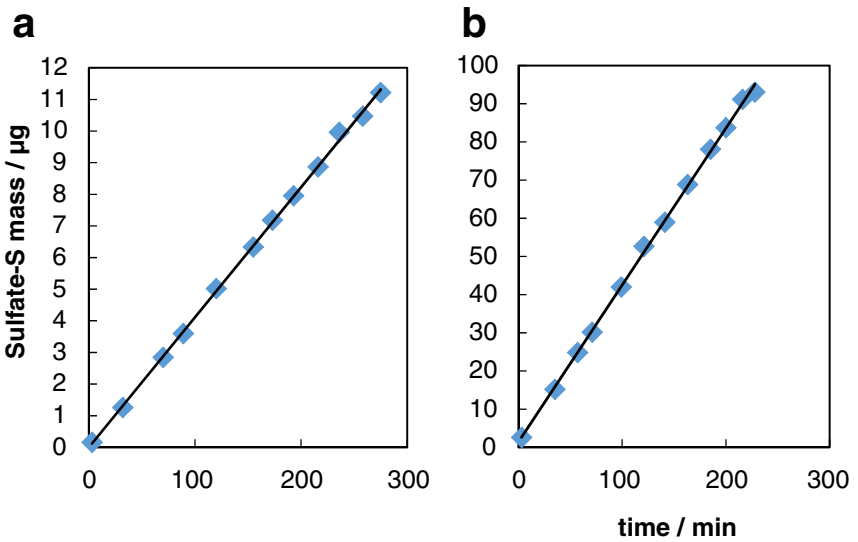

C

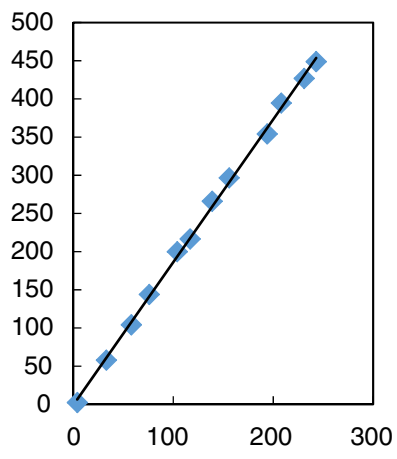

combined uncertainty of an individual $c_{\text {DGT }}$ value was on average $8 \%\left(u_{c}, k=1\right)$. With respect to the combined uncertainty, the $c_{\mathrm{DGT}} / c_{\text {soln }}$ was not significantly different from 1 for immersion solution $\mathrm{pH}$ values between 3 and 9 (Fig. 4). Slightly larger deviations of the mean $c_{\mathrm{DGT}} / c_{\mathrm{Soln}}$ values from 1 were observed in the $\mathrm{pH}$ range 3-5 compared to higher $\mathrm{pH}$ values.

\section{Gel capacity}

The relative combined uncertainty of the theoretical uptake line was $9.5 \%$, with the $\mathrm{S}$ measurement uncertainty being the main contributor $(>75 \%)$. The experimentally determined $\mathrm{S}$ uptake onto the gel after $24 \mathrm{~h}$ DGT deployment was up to $130 \pm 11 \mu \mathrm{g} \mathrm{S}$ per disc and is in agreement with the theoretical value of $144 \pm 13 \mu \mathrm{g} \mathrm{S}$ per disc (Fig. 5a). The concentration of $\mathrm{Cl}^{-}$declined to $<\mathrm{LOD}$ (LOD, $10 \mu \mathrm{g} \mathrm{L}^{-1}$ ) after $15 \mathrm{~h}$ of DGT exposure, which was expected as the resin was used in its $\mathrm{Cl}^{-}$ form. The phosphate uptake reached its maximum after $24 \mathrm{~h}$ $(6.3 \pm 1.6 \mu \mathrm{g} P$ per disc). At deployment times of 39 and $48 \mathrm{~h}$, the $\mathrm{P}$ taken up by DGT declined to around half the maximum value $(2.8 \pm 0.7 \mu \mathrm{g}$ per disc and $3.3 \pm 1.0 \mu \mathrm{g}$ per disc, respectively) (Fig. 5b).

The characteristics of the method are summarized in Table 2.

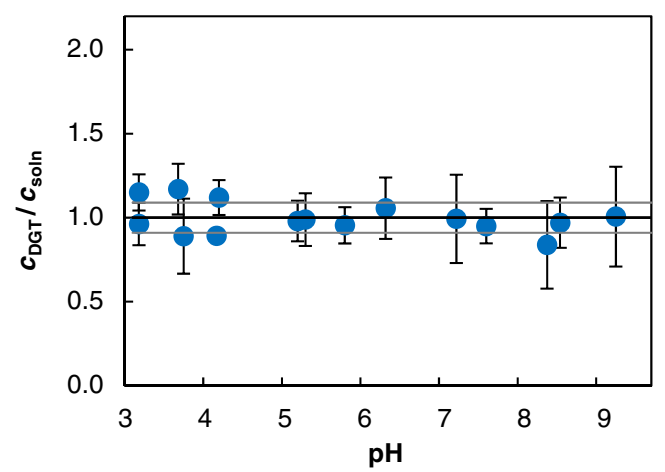

Fig. 4 Determination of the $\mathrm{pH}$ working range. The error bars are $u_{c}$, the 1.0 line is displayed with its uncertainty $\left(u_{c}=0.089\right)$

\section{Comparison of DGT S with conventional soil S extraction techniques}

DGT $S$ extracted from the experimental soils ranged between 1.5 and $20.2 \mu \mathrm{g}$, corresponding to $c_{\text {DGT }}$ values of $0.23-$ $3.16 \mathrm{mg} \mathrm{L}^{-1}$. The linear correlation coefficients of DGT-S with $\mathrm{S}$ extracted by the $\mathrm{MCP}$ and $\mathrm{KCl}-40$ methods were low with $r^{2}=0.40(\mathrm{MCP})$ and $r^{2}=0.18$ (KCl-40) (Fig. 6).

\section{Discussion}

The elevated background $\mathrm{S}$ levels on the unwashed protective membrane (Fig. 2) indicate the necessity to clean the membrane before use in order to prevent contamination of the
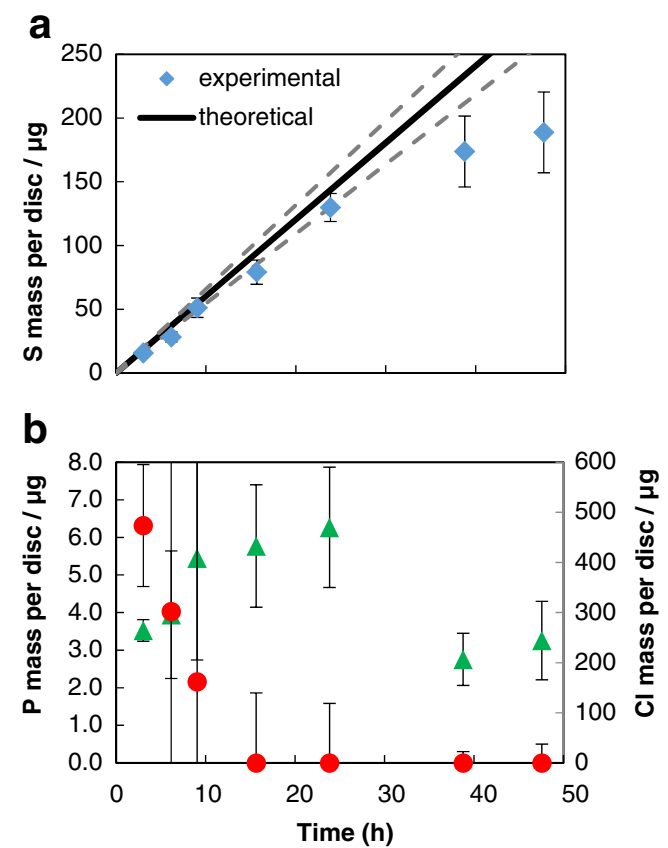

Fig. 5 Sulfate uptake capacity. a Experimental (blue diamonds) and theoretical (black line $\pm 9 \%, u_{c}$ ) sulfate uptake over time. b Release of chloride (red points) and phosphorus uptake (green triangles) by the gel over time. Error bars are $u_{c}$ 
Table 2 DGT method characteristics

\begin{tabular}{lllll}
\hline Parameter & Abbreviation & Value & Type of uncertainty & Unit \\
\hline Method limit of detection & MDL & 0.29 & - & $\mathrm{mg} \mathrm{S} \mathrm{L}^{-1}$ \\
Method blank resin gel loading & - & $1.64 \pm 0.63$ & $\mathrm{SD}(n=4)$ & $\mu \mathrm{g} \mathrm{S}$ per disc \\
Diffusion coefficient & $D$ & $9.83 \times 10^{-6} \pm 0.35 \times 10^{-6}$ & $u_{c}(k=1)$ & $\mathrm{cm}^{2} \mathrm{~s}^{-1}$ \\
Elution efficiency & $R$ & $0.909 \pm 0.016$ & $u_{c}(k=1)$ & - \\
Gel capacity & - & $130 \pm 11$ & $\operatorname{SD}(n=3)$ & $\mu \mathrm{g} \mathrm{S}$ per disc \\
\hline
\end{tabular}

sampler. No background $\mathrm{S}$ was detectable in the acid-washed membranes as well as in diffusive gel eluates. While $\mathrm{S}$ was determined in blank resin gel disc eluates, considerably more $\mathrm{S}$ was eluted from discs retrieved from non-deployed method blank DGT units. This indicates, that sampler assembly and handling may increase the background sulfate level on the resin gel, most likely due to sulfate being a very abundant chemical species even in a clean room laboratory setting. Monitoring of the sulfate background on method blanks is therefore a necessity for DGT sulfate analyses. However, the $\mathrm{S}$ masses accumulated on the resin gels in the soil experiment were 4-55 times higher than the blank $\mathrm{S}$ gel loading, indicating that this slightly elevated background $\mathrm{S}$ value is not a problem for soil sulfate testing using DGT.

The determined diffusion coefficient value $\left(9.83 \times 10^{-6} \pm\right.$ $0.35 \times 10^{-6} \mathrm{~cm}^{2} \mathrm{~s}^{-1}$ ) was approximately $91.4 \%$ of the $\mathrm{SO}_{4}{ }^{2-}$ $D_{25}$ values for pure water $\left(10.8 \times 10^{-6}[25]\right)$ or seawater $(10.7 \times$
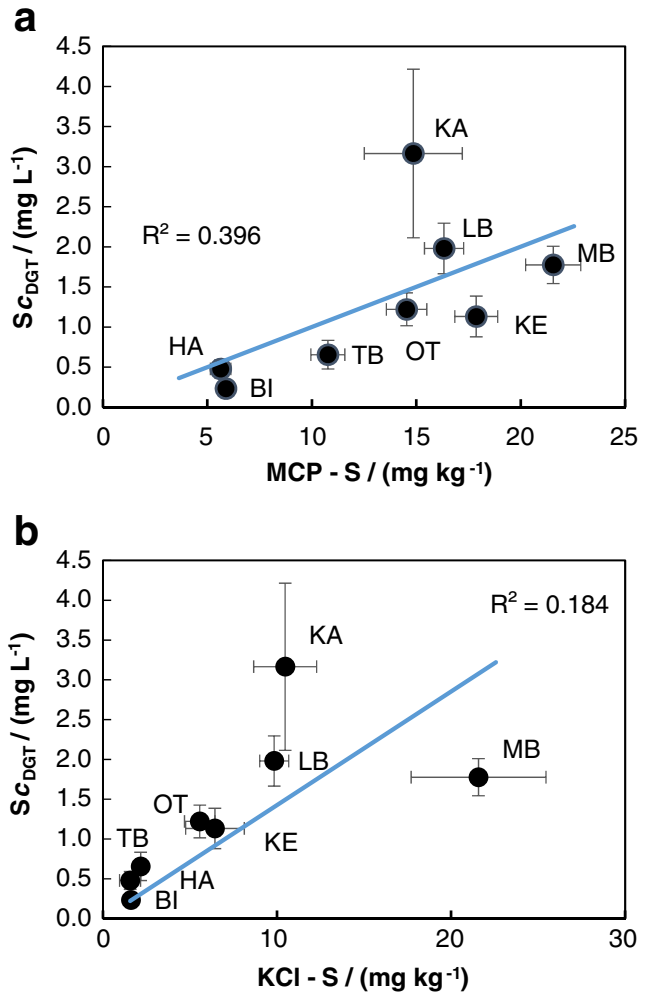

Fig. 6 Correlation of DGT-S with S extracted by a MCP and $\mathbf{b}$ KCl-40. The line represents the linear regression line. Error bars are $1 \mathrm{SD}$
$10^{-6}[26]$ ), which is expected as solute diffusion coefficients are generally lower in APA diffusive gels than in water [20,27]. This is caused most likely by tortuous diffusion pathways through the acrylamide gel matrix. $D$ was the same for all test solutions $(1,10$, and $45 \mathrm{mg} \mathrm{L}^{-1} \mathrm{~S}$ ) indicating that $\mathrm{SO}_{4}{ }^{2-}$ diffusivity is not concentration dependent, which is a pre-requirement for quantification of labile $\mathrm{SO}_{4}{ }^{2-}$ by DGT.

The elution efficiency $(90.9 \pm 1.6 \%)$ showed that the sampled $\mathrm{SO}_{4}{ }^{2-}$ is not completely eluted from the resin gel. However, as the elution efficiency is almost constant (low combined uncertainty), a correction factor can be applied for the calculation of $c_{\text {DGT }}$. Higher elution efficiency ( 100\%) can be obtained if the sorbent in the resin gel is dissolved during elution, as is the case for ferrihydrite resin gels that are used for phosphate sampling by DGT [27], or when the resin gel is digested [18]. Application of an ion exchange resin in DGT leads to generally lower recoveries, e.g., when Chelex is used for cation sampling (70-82\% recovery [10]).

DGT can be expected to perform well for $\mathrm{SO}_{4}{ }^{2-}$ quantification in the $\mathrm{pH}$ range between 3 and 9. This wide $\mathrm{pH}$ range enables the application of the developed method to both arable and acidic (e.g., forest) soils. However, a larger uncertainty must be taken into account for the $\mathrm{pH}$ range 3-5.

The relative expanded uncertainty of an individual $c_{\text {DGT }}$ value estimated in this study (typically $16 \%, U_{\text {rel }} k=2$ ) was higher than the $10 \%$ expanded uncertainty $\left(U_{\text {rel }}, k=2\right)$ reported by Kreuzeder et al. [21]. The main contributor (up to $40 \%$ ) to the $8 \%$ combined uncertainty was the uncertainty of the diffusion coefficient. The relative uncertainty of the $D_{25}$ for $\mathrm{SO}_{4}{ }^{2-}$ in hydrogel $(4 \%)$ is twofold larger than the relative uncertainties of $D_{\text {gel }}$ reported in [21].

The capacity of the gel was $130 \mu \mathrm{g}$ S per gel disc, which equals $41 \mu \mathrm{g} \mathrm{S} \mathrm{cm}{ }^{-2}$ gel (calculated based on the sampling window area of $3.14 \mathrm{~cm}^{2}$ ) in the synthetic soil solution. As this value was obtained under high sulfate:anion ratios, the reported capacity can be considered a conservative lower-limit estimate. Based on the DGT soil analyses done in this study, and some of our ongoing work in which we obtained a maximum DGT S uptake of about $85 \mu \mathrm{g}$ for $24 \mathrm{~h}$ deployments, this capacity is well suited for analyzing soil S using DGT.

In the capacity test, $\mathrm{PO}_{4}{ }^{3-}$ was continuously bound to the gel during the first $24 \mathrm{~h}$. However, the mass of $\mathrm{P}$ measured later on declined to around half the maximum value. This behavior 
indicates that $\mathrm{SO}_{4}{ }^{2-}$ is taken up preferentially, as it replaced previously sorbed phosphate when the total gel loading was already high. The decrease of the $\mathrm{Cl}^{-}$concentration in the eluates with time was expected as the chloride form of Amberlite IRA- 400 was used and $\mathrm{Cl}^{-}$was continuously replaced by other anions. The discrepancy between the sum of the bound $\mathrm{SO}_{4}{ }^{2-}$ and $\mathrm{PO}_{4}{ }^{3-}$ and the exchanged $\mathrm{Cl}^{-}$can be explained by $\mathrm{NO}_{3}{ }^{-}$bound on the resin. Although it can be assumed that $\mathrm{NO}_{3}{ }^{-}$does not bind strongly to the resin and would be exchanged by $\mathrm{SO}_{4}{ }^{2-}$ present in the solution, its concentration in the synthetic soil solution was four times higher than the $\mathrm{SO}_{4}{ }^{2-}$ concentration. Part of the $\mathrm{Cl}^{-}$was therefore probably exchanged for $\mathrm{NO}_{3}^{-}$. It was not possible to confirm this assumption as $1 \mathrm{~mol} \mathrm{~L}^{-1} \mathrm{HNO}_{3}$ was used as the eluting agent.

The developed method was successfully applied for a small set of selected soil samples. Sulfur sampled by DGT did not correlate well with that extracted by MCP and $\mathrm{KCl}-40$. The low correlation coefficients between MCP and DGT $\left(r^{2}=0.40\right)$ and KCl-40 and DGT $\left(r^{2}=0.18\right)$ are likely linked to the differential sampling mechanisms of the methods applied. While extractions are based on a quasi-equilibrium between soil and extractant, DGT acts as an infinite sink technique that samples labile soil sulfate [13]. Visual inspection of Fig. 6 suggests that the two soils (KA, MB) might be outliers in the correlation. Excluding the soils KA and MB from the correlation between $\mathrm{KCl}-40$ and DGT would increase the correlation coefficient to $r^{2}=0.94$. If the KA soil was excluded from the comparison of DGT with MCP, the correlation coefficient would increase to $r^{2}=0.75$. However, neither a statistical outlier test (Grubbs' test, $p>0.05$ ) identified KA and MB as outliers nor does the geochemical composition of the soil samples suggest a different behavior than the other soils. Clearly, a larger set of samples is needed to better understand the relation of the DGT and MCP/KCL-40 sampled sulfate fractions.

It has been shown that neither MCP nor KCl-40 corresponds well to the $\mathrm{SO}_{4}{ }^{2-}$ uptake of plants [15], while DGT has been shown to be a good predictor of plant-available nutrients and contaminants [28]. In an agronomical evaluation of the presented DGT method as a soil S test, Mason et al. [29] found that DGT predicted maize relative yield and S uptake better than the two extraction methods. Together with reports that DGT and plants utilize the same soil phosphate pools, while chemical batch extractions do not [12, 13], this indicates that DGT S uptake from soil resembles that of plants very well, while batch extraction methods are not efficient predictors of plant $\mathrm{S}$ uptake. Our study provides a first indication of the potential of DGT-S in soil testing; however, further investigation and validation of this approach is warranted.

\section{Conclusions}

The presented DGT method showed great potential for soil $\mathrm{SO}_{4}{ }^{2-}$ sampling. The preference of the applied resin gel towards $\mathrm{SO}_{4}{ }^{2-}$ over other anions typically present in soil and soil solution, and the high capacity of the gel allow for $\mathrm{SO}_{4}{ }^{2-}$ sampling from soils of a pH range between 3 and 9.

As conventional extraction methods are not very representative of plant available soil $\mathrm{S}$, the simple and quick DGT technique can deliver significant benefits. However, it has to be proved whether DGT samples the same soil S pool as plants. Direct comparison of plant and DGT uptake applying isotopic marking or analysis of stable $\mathrm{S}$ isotopes will enable this assumption to be tested.

Acknowledgments Open access funding was provided by the University of Natural Resources and Life Sciences Vienna (BOKU). This study was funded by the Austrian Science Fund (FWF): P23861B16 and P27571-BBL. Melanie Diesner is acknowledged for her support in the laboratory work, and Christoph Hoefer and Andreas Kreuzeder are acknowledged for their expert's opinions on the DGT technique.

\section{Compliance with ethical standards}

Conflict of interest The authors declare that they have no conflict of interest.

Open Access This article is distributed under the terms of the Creative Commons Attribution 4.0 International License (http:// creativecommons.org/licenses/by/4.0/), which permits unrestricted use, distribution, and reproduction in any medium, provided you give appropriate credit to the original author(s) and the source, provide a link to the Creative Commons license, and indicate if changes were made.

\section{References}

1. Likens G, Driscoll C, Buso D, Mitchell M, Lovett G, Bailey S, et al. The biogeochemistry of sulfur at Hubbard Brook. Biogeochemistry. 2002;60:235-316.

2. Eriksen J, Thorup-Kristensen K, Askegaard M. Plant availability of catch crop sulfur following spring incorporation. J Plant Nutr Soil Sci. 2004;167:609-15.

3. Hanousek O, Berger TW, Prohaska T. MC ICP-MS $\delta^{34} \mathrm{~S}_{\mathrm{VCDT}}$ measurement of dissolved sulfate in environmental aqueous samples after matrix separation by means of an anion exchange membrane. Anal Bioanal Chem. 2016;408:399-407.

4. Tabatabai MA. Sulfur. In: Sparks DL, Page AL, Helmke PA, Loeppert RH, Soltanpour PN, Tabatabai MA, et al., editors. Methods of soil analysis. Part 3. Chemical methods. Madison: Soil Science Society of America and American Society of Agronomy; 1996. p. 921-60.

5. Shan X, Chen B, Jin L, Zheng Y, Hou X, Mou S. Determination of sulfur fractions in soils by sequential extraction, inductively coupled plasma-optival emission spectrometry and ion chromatography. Chem Speciat Bioavailab. 1992;4:97-103.

6. Blair GJ, Chinoim N, Lefroy RDB, Anderson GC, Crocker GJ. A soil sulfur test for pastures and crops. Aust J Agric Res. 1991;29:619-26.

7. Schoenau JJ, Qian P, Huang WZ. Ion exchange resin membranes as plant root simulators. Proc. soils and crops workshop 1993. Saskatoon: University of Saskatchewan; 1993.

8. Fernandes ML, Coutinho J. Anion and cation exchange resin membranes to assess the phosphorus status of some Portuguese soils. Commun Soil Sci Plant. 1997;28:483-95.

9. Mason SD, Hamon RE, Zhang H, Anderson J. Investigating chemical constraints to the measurement of phosphorus in soils using 
DGT (diffusive gradients in thin-films) and resin methods. Talanta. 2008;74:779-87.

10. Zhang H, Davison W. Performance characteristics of diffusion gradients in thin films for the in situ measurement of trace metals in aqueous solution. Anal Chem. 1995;67:3391-400.

11. Degryse F, Smolders E, Zhang H, Davison W. Predicting availability of mineral elements to plants with the DGT technique: a review of experimental data and interpretation by modelling. Environ Chem. 2009;6:198-218.

12. Six L, Pypers P, Degryse F, Smolders E, Merckx R. The performance of DGT versus conventional soil phosphorus tests in tropical soils - an isotope dilution study. Plant Soil. 2012;359:267-79.

13. Mason SD, McLaughlin MJ, Johnston C. Soil test measures of available $\mathrm{P}$ (Colwell, resin and DGT) compared with plant $\mathrm{P}$ uptake using isotopic dilution. Plant Soil. 2013;373:711-22.

14. Mason SD, McNeill A, McLaughlin MJ, Zhang H. Prediction of wheat response to an application of phosphorus under field conditions using diffusive gradients in thin-films (DGT) and extraction methods. Plant Soil. 2010;337:243-58.

15. Guppy C, Blair G. Predictive value of resin extraction to determine sulfur and phosphorus response of maize in a range of soils from the New England Tablelands of NSW, Australia. 19th World Congress of Soil Science; 1 - 6 August 2010; Brisbane, Australia 2010.

16. Teasdale PR, Hayward S, Davison W. In situ, high-resolution measurement of dissolved sulfide using diffusive gradients in thin films with computer-imaging densitometry. Anal Chem. 1999;71:2186-91.

17. Santner J, Prohaska T, Luo J, Zhang H. Ferrihydrite containing gel for chemical imaging of labile phosphate species in sediments and soils using diffusive gradients in thin films. Anal Chem. 2010;82:7668-74.

18. Kreuzeder A, Santner J, Prohaska T, Wenzel WW. Gel for simultaneous chemical imaging of anionic and cationic solutes using diffusive gradients in thin films. Anal Chem. 2013;85:12028-36.
19. Oster GK, Oster G, Prat G. Dye-sensitized photopolymerization of acrylamide. Anal Chem. 1957;79:595-8.

20. Zhang H, Davison W. Diffusional characteristics of hydrogels used in DGT and DET techniques. Anal Chim Acta. 1999;398:329-40.

21. Kreuzeder A, Santner J, Zhang H, Prohaska T, Wenzel WW. Uncertainty evaluation of the diffusive gradients in thin films technique. Environ Sci Technol. 2015;49:1594-602.

22. Blume H-P, Brümmer GW, Horn R, Kandeler E, Kögel-Knabner I, Kretzschmar R, et al. Scheffer/Schachtschabel: Lehrbuch der Bodenkunde. Heidelberg: Springer Spektrum Akademischer Verlag; 2010.

23. Linsinger T. Application note 1: comparison of a measurement result with the certified value. European Reference Materials: Geel; 2005.

24. Rayment GE, Higginson FR. Australian laboratory handbook of soil and water chemical methods. Sydney: Inkata Press; 1992.

25. Lai TM, Mortland MM. Self-diffusion of exchangeable cations in bentonite. In: Swineford A, editor. Clays and clay minerals. Leipzig: Pergamon Press; 1962. p. 229-48.

26. Li HY. Diffusion of ions in sea water and in deep sea sediments. Geochim Cosmochim Acta. 1974;38:703-14.

27. Zhang H, Davison W, Gadi R, Kobayashi T. In situ measurement of dissolved phosphorus in natural waters using DGT. Anal Chim Acta. 1998;380:29-38.

28. Zhang H, Davison W. Use of diffusive gradients in thin-films for studies of chemical speciation and bioavailability. Environ Chem. 2015;12:85-101.

29. Mason SD, McNeill A, Zhang Y, McLaughlin MJ, Guppy C. Application of diffusive gradients in thin-films (DGT) to measure potassium and sulphur availability in agricultural soils. 16th Agronomy Conference 2012; 14-18th October 2012. Armidale: University of New England; 2012. 